\title{
Designing the optimal robotic milking barn by applying a queuing network approach
}

\author{
I. Halachmi ${ }^{\mathrm{a}, \mathrm{b}, \mathrm{c}, *}$, I.J.B.F. Adan ${ }^{\mathrm{d}}$, J. van der Wal ${ }^{\mathrm{d}}$, \\ P. van Beek ${ }^{\mathrm{e}}$, J.A.P. Heesterbeek ${ }^{\mathrm{f}}$ \\ ${ }^{a}$ Agricultural Research Organization, ARO, Institute of Agricultural Engineering, the Volcani Center, Israel \\ ${ }^{\mathrm{b}}$ Institute of Agricultural and Environmental Engineering (IMAG), Wageningen, The Netherlands \\ ${ }^{\mathrm{c}}$ Department of Agricultural Engineering and Physics, Wageningen University, Wageningen, The Netherlands \\ ${ }^{\mathrm{d}}$ Faculty of Mathematics and Computing Science, Eindhoven University of Technology (TUE), \\ Eindhoven, The Netherlands \\ ${ }^{\mathrm{e}}$ Department of Mathematics, Wageningen Agricultural University (WAU), Wageningen, The Netherlands \\ ${ }^{\mathrm{f}}$ Faculty of Veterinary Medicine, University of Utrecht, Utrecht, The Netherlands
}

\begin{abstract}
The design of various conventional dairy barns is based on centuries of experience, but there is hardly any experience with robotic milking barns (RMB). Furthermore, as each farmer has his own management practices, the optimal layout is 'site dependent'. A new universally applicable design methodology has been developed, to overcome this lack of experience with RMBs and to facilitate the designing of their optimal layout. This model for optimizing facility allocation, based on cow behaviour, welfare needs, and facility utilization, uses queuing network theory, Markov process, and heuristic optimization. The methodology has been programmed into a software application, supporting the design process. On a particular farm, presented later as a case study, numerical results include: if the herd contains more than 50 cows, the forage-lane utilization is greater than $70 \%$ (or idle time is less than $30 \%$ ). To meet animal-welfare demands, the herd size should not exceed 60 cows. Therefore, the herd should comprise 50-60 cows. In the second scenario examined, the average robot idle time was $25 \%$, queue length was three cows, and each cow waited for about $3 \mathrm{~min}$ at the robot. It is still uncommon to apply techniques from queuing-network theory to livestock housing, and this study demonstrates their potential as practical design tools that meet both economic and animal welfare needs.
\end{abstract}

(C) 2003 Elsevier Science Ltd. All rights reserved.

Keywords: Automatic milking; Dairy cow; Farm design; Simulation; Animal behaviour model

* Corresponding author at present address: Farm 27, Kfar Yehoshua, Zip 30063, Israel. Fax + 972-49531456.

E-mail address: halachmi@volcani.agri.gov.il (I. Halachmi).

0308-521X/03/\$ - see front matter (C) 2003 Elsevier Science Ltd. All rights reserved. 


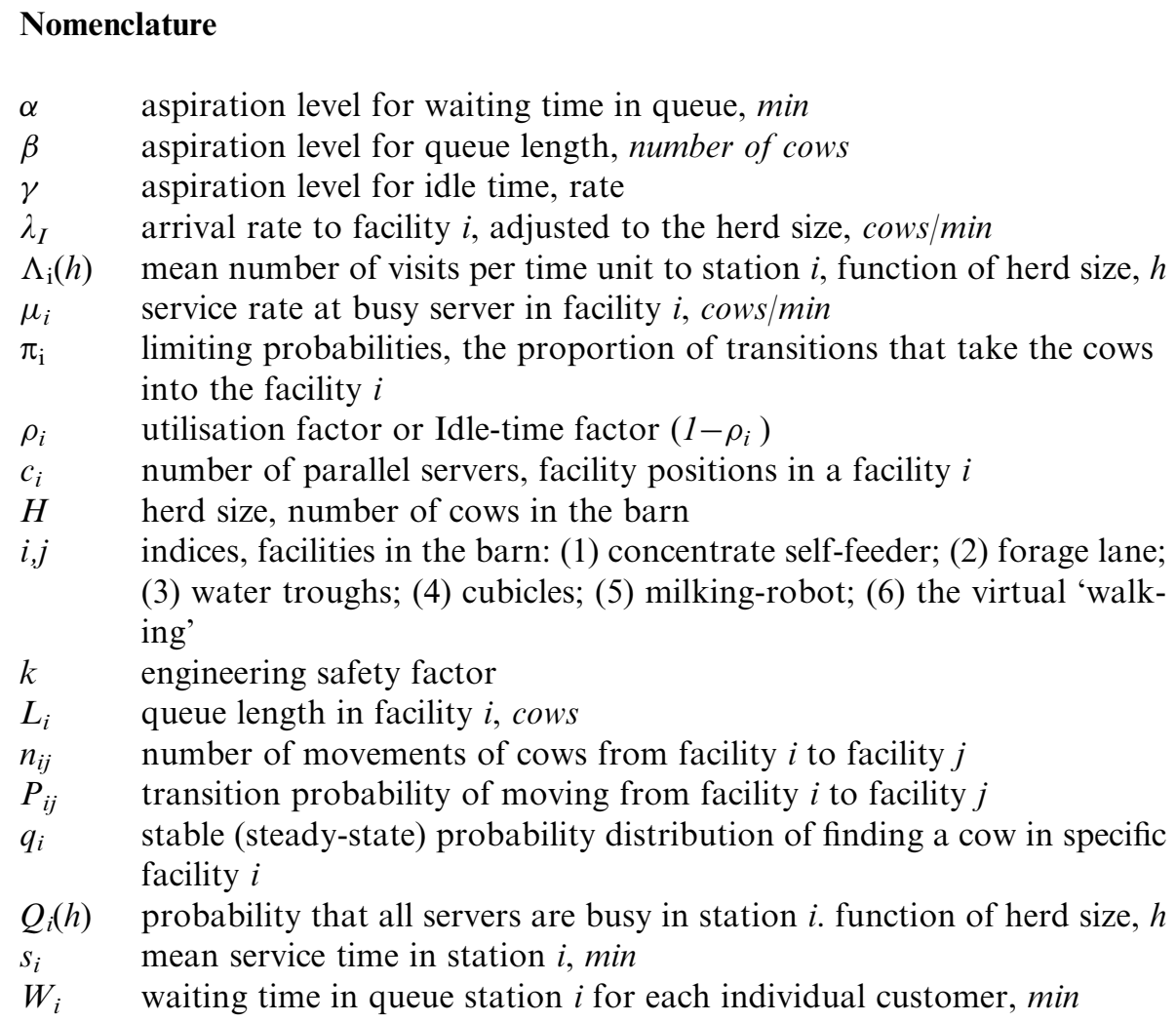

\section{Introduction}

Robotic milking is relatively new. It affects factors such as cow behaviour, farm routine, feeding procedures, and management practices that determine the barn layout. The design of milking-parlour-oriented barns is based on decades of experience, but there is no such experience with robotic barns. Furthermore, the optimal layout is 'site dependent', because each farmer has his own management attitude, feeding routine, cow-traffic preference, existing facilities, and many more individual characteristics. In order to overcome this lack of experience and to be able to design an optimal layout, suitable for any farmer or site a novel approach to planning is needed.

Halachmi et al. (2000a) concluded that under certain conditions, cows' voluntary visits to the milking robot even out facility usage throughout the day and night, to establish a continuous-time stochastic process. They quantified this process in terms of theoretical probability distributions (PD), and thus opened up the opportunity to treat a barn as a queuing network, and to design it by using queuing models.

In a previous paper, Halachmi et al. (2000b) described the development of a closed queuing network model for a robotic milking barn (RMB), to evaluate performance 
criteria, such as queue length, waiting time and facility utilization. In order to incorporate these performance criteria into a practical design tool, the first step is to analyse cow 'flow' between barn facilities, by means of a Markov process (Section 3.1). It is assumed that each facility acts as a stochastically independent unit, therefore, each facility is analysed separately, using queuing theory (Section 3.2). Section 3.3 develops an 'aspiration-level' model, which forms the design criteria and provides an analysis of the overall performance of the barn. Section 4 lists the validation steps.

The present study is part of a wider research project whose goal is to develop a design tool for optimizing RMBs, based on cow welfare needs and facility utilization (Halachmi, 1999). The number of facilities per head has to be calculated for an $\mathrm{RMB}$, and the queuing model appears to be a practical tool. In Section 6, tables, figures, and the graphical user interface (GUI) are used to explain the design tool and its scope in a particular practical situation.

\section{Literature review}

At the end of 1997 around 175 milking robots were in use on Dutch commercial farms (Rossing et al., 1998); at the end of 1999 there were over 300 such systems in operation (Lind et al., 2000), and more are expected to be introduced each year, both in the Netherlands and worldwide. Robotic milking increases milking frequency, which reduces the stress on the udders of high-yielding cows, and increases their milk yield; it also reduces human mental and physical labour. If the cows choose to be milked more frequently than twice daily, we would expect an increase of up to $15 \%$ in milk yield (Hillerton and Winter, 1992), whereas attendance less than twice per day would reduce milk yield and might increase the incidence of mastitis (Wilde and Peaker, 1990). However, the motivation to be milked is relatively weak (Prescott et al., 1998). In a conventional barn, the milker brings the cows to a waiting area from which they are forced to enter the milking parlour, whereas in a milking robot situation, cows are expected to visit a milking stall voluntarily. The barn layout (facility allocation, robot location, and bottleneck prevention) affects the robot attractiveness and the cows' visiting frequency. It is, therefore, crucial to plan the layout carefully (Ketelaar de Lauwere et al., 1996, 1998; Hogeveen et al., 1998; Sfefanowska et al., 1997; Ipema, 1997; Rossing and Hogewert, 1997; Sonck, 1996; Devir, 1995; Armstrong et al., 1992; van der Linde and Lubberink, 1992). Other facilities that have to be included in the design of the RMB, in addition to the milking robot stalls, are the concentrate self-feeder (CSF; Livshin et al., 1995), forage-lane eating positions (Wierenga and Hopster, 1991; Menzi and Chase, 1994), water troughs (Murphy, 1992; Silanikove et al., 1997; Shalit et al., 1991), and cubicles (Wierenga and Hopster, 1990; Wierenga and Metz, 1986). Traditional ratios of these facilities established for a milking-parlour barn are usually: one cubicle per cow, one forage-lane position per cow, and one CSF per 20-25 cows (Lindley and Whitaker, 1996). However, it has already been verified that under certain conditions, it is possible to accommodate more cows than cubicles or feeding stands without 
major problems. (Acillona and Perez, 1996a, b), but since robotic milking is so new, the experience in designing RMBs is, as yet, virtually non-existent.

In the 1960s, stochastic models such as queuing theory were found to be an effective tool to study the performance of complex communication systems, networks, resource allocation, logistics, and complicated interconnections in a system. Thousands of research papers, formulating and analysing queuing models, have already appeared in the literature, and many more are being published each year (van Beek, 1975; Kleinrock, 1975). So far, however, queuing theory has not been used to design barns.

\section{Material and methods}

\subsection{Interactions between barn facilities and cows; applying Markov process analysis}

The cows determine how the use of the various facilities is linked, after having been serviced in facility $i$, the cow proceeds to facility $j$. The transition probabilities $P_{i j}$, based on a discrete time Markov chain (Hillier and Lieberman, 1986), can be calculated:

$$
P_{i j}=\frac{n_{i j}}{\sum_{j} n_{i j}}, \quad \mathrm{i}, \mathrm{j}=1, \ldots, 6,
$$

where $n_{i j}$ denotes the number of movements from facility $i$ to $j$ measured by Halachmi et al. (2000a), and $\sum_{j} n_{i j}$ is the total number of movements from $i$. The transition probabilities $P_{i j}$ are shown in Table 1 . The limiting probability $\pi_{i}$, the proportion of transitions that take the cows into the facility $i$, is the unique non-negative solution of

$$
\left\{\begin{array}{l}
\pi_{i}=\sum_{j=1}^{6} \pi_{j} P_{j i}, \quad i=1, \ldots, 6 . \\
\sum_{i=1}^{6} \pi_{i}=1
\end{array}\right.
$$

Table 1

Transition probabilities (matrix) between facilities in the barn

\begin{tabular}{lllllll}
\hline \multirow{2}{*}{ Departure facility (from...) } & \multicolumn{5}{l}{ Probabilities of movement to barn facilities (to...) } \\
\cline { 3 - 6 } & & Concentrate (1) & Forage (2) & Water (3) & Cubicles (4) & Milking (5) \\
\hline Concentrate & $(1)$ & 0.03 & 0.62 & 0.11 & 0.24 & 0 \\
Forage & $(2)$ & 0 & 0.03 & 0.16 & 0.79 & 0.01 \\
Water & $(3)$ & 0.02 & 0.45 & 0.10 & 0.15 & 0.28 \\
Cubicles & $(4)$ & 0 & 0.16 & 0.35 & 0.08 & 0.41 \\
Milking & $(5)$ & 0.90 & 0.05 & 0.01 & 0.03 & 0.01 \\
\hline
\end{tabular}


Based on continuous-time Markov process (e.g. Grimmett and Stirzaker, 1992; Ross, 1997), and the mean service time $\left(s_{i}\right)$ at the various facilities, the Stable (steady-state) probability distribution $\left(q_{i}\right)$ gives the fraction of the time that a cow is expected to spend in each of the six facilities.

$$
q_{i}=\frac{\pi_{i} s_{i}}{\sum_{j} \pi_{j} s_{j}} .
$$

The experiment (Halachmi et al., 2000a) was carried out with maximum availability of facilities for the cows (significantly, more cows than facilities); no queue or pressure on a facility ever happened during the experiment. Therefore, the service time $\left(s_{i}\right.$, as determined in this experiment) is an upper estimate, which satisfies the animals' welfare needs, independently of the herd size $(H)$ or barn layout. It does not imply that the process settles down into one state; on the contrary, the cows continue to make transitions from facility to facility.

In structural engineering, a 'safety-factor', $k>1$ is frequently used, therefore, the hypothetical optimum number of servers $\left(c_{i}^{*}\right)$ can be expressed as:

$$
c_{i}^{*}=k q_{i} H, \quad i=1, \ldots, 5 .
$$

For example, if a farmer has 100 cows, and $k$ is set at 1.2, then, based on Fig. 1, the optimal number of cubicles is $1.2 \times 0.61 \times 100 \cong 74$, and the optimal number of forage-lane positions is $1.2 \times 0.13 \times 100 \cong 16$ (facility allocation is rounded up). But, Eq. (4) has two drawbacks.

1. The utilization levels $\left(\rho_{i}\right)$ becomes the same for all the facilities in the barn. This means that an expensive facility and a relatively cheap one are treated the same (for instance, a milking robot might cost 0.25 million NLG, whereas a water trough costs only a few hundred NLG).

2. The numbers of facilities are integers, and the vector q has real values. For example, 2.2 robots would not be practicable, and either '2' or ' 3 ' must be chosen.

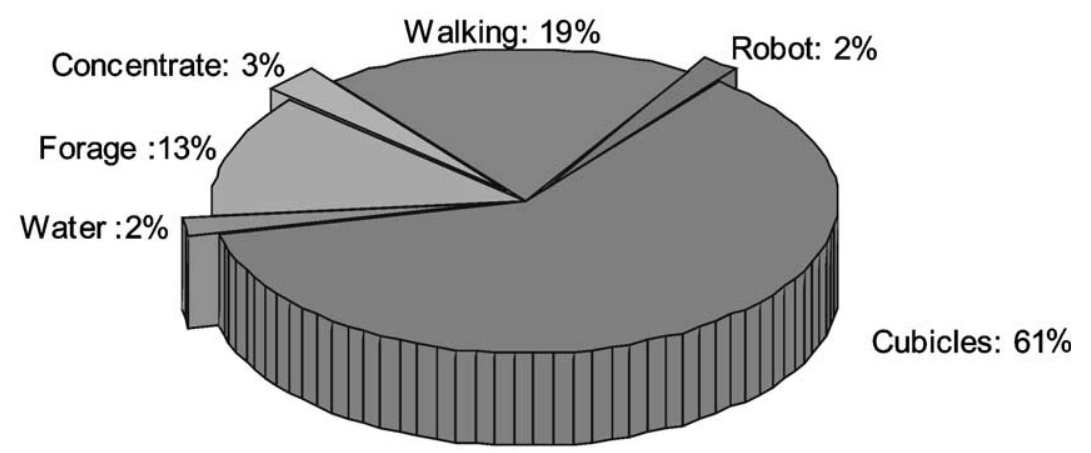

Fig. 1. Stable probability distribution $\left(q_{i}, \%\right)$. 
The 'aspiration-level model' and 'queuing model' (outlined later), combined with a graphical user interface (GUI) overcomes these drawbacks and gives the designer additional freedom in fine-tuning the allocation of facilities while remaining near the balanced design dictated by the stable distribution.

\subsection{Using a queuing network model to evaluate barn performance}

The barn is actually a queuing network, i.e. it contains a series of service facilities ('stations'), at some or all of which, cows must receive service; for example, consumption of concentrate, forage and water are physiologically linked. It is, therefore, necessary to study the entire network (the barn). Fig. 2 outlines the network model of a robotic milking barn; it can be seen that cows prefer to remain in the cubicles longer (service time $1 / \mu_{4}=59.42 \mathrm{~min}$ ) than at the other facilities.

Some of our underlying PDs are of a general type (Halachmi et al., 2000a), therefore, an exact analysis of our network is impossible (Baskett et al., 1975; Gross and Harris, 1998; Lemoine, 1977; van Vliet, 1991). We therefore have to rely on

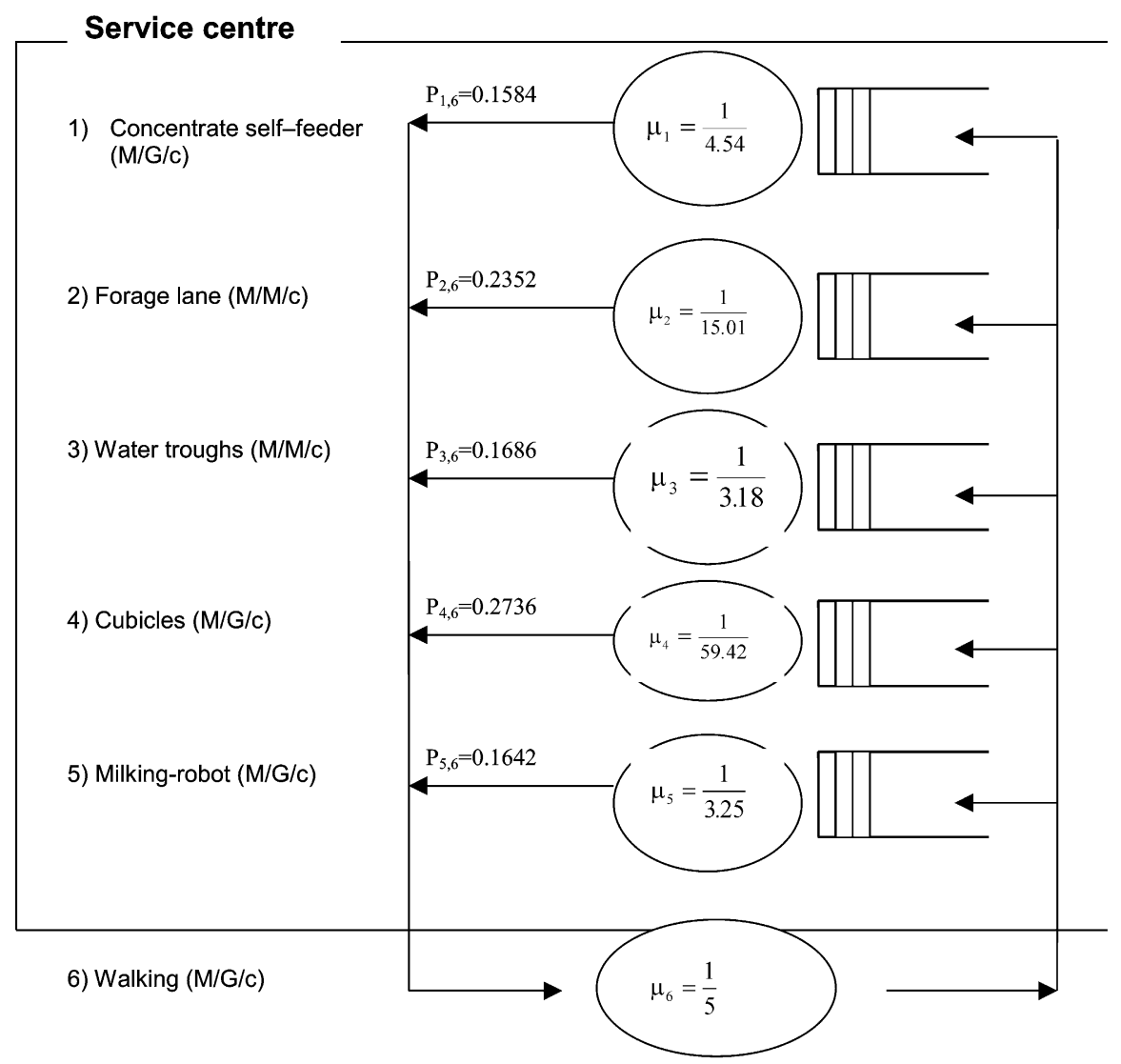

Fig. 2. Network model of robotic milking barn, service rates $\left(\mu_{i}\right)$, and transition probabilities $\left(P_{i j}\right)$. 
methods that approximate the behaviour of the network. For practical purposes, statistics such as mean queue length, waiting times and utilization are needed. The so-called approximated-mean-value analysis (AMVA) given by Halachmi et al. (2000b) provides the desired statistics, and establishes the basis for heuristic extension, The AMVA algorithm is summarised here.

Step 1. Initialisation: $L_{i}(0)=\mathrm{Q}_{i}(0)=0$ for all $i$

Step 2. For $h=1,2, \ldots, H$ compute for $i=1, \ldots, 6$

$$
\begin{aligned}
W_{i}(H) & =Q_{i}(h-1) \frac{R_{i}}{c_{i}}+L_{i}(h-1) \frac{s_{i}}{c_{i}}, \\
S_{i}(h) & =W_{i}(h)+s_{i} \\
\Lambda_{i}(h) & =\frac{v_{i} h}{\sum_{i=1}^{6} v_{i} S_{i}(h)} \\
L_{i}(h) & =\Lambda_{i}(h) W_{i}(h) \\
\rho_{i}(h) & =\Lambda_{i}(h) \frac{s_{i}}{c_{i}} \\
Q_{i}(h) & =0, \quad \text { if } h<c_{i} \\
& =\frac{\left(c_{i} \rho_{i}(h)\right)^{c_{i}}}{c_{i} !}\left\{\left(1-\rho_{i}(h)\right) \sum_{k=0}^{c_{i}-1} \frac{\left(c_{i} \rho_{i}(h)\right)^{k}}{k !}+\frac{\left(c_{i} \rho_{i}(h)\right)^{c_{i}}}{c_{i} !}\right\}^{-1}, \text { if } h \geqslant c_{i} .
\end{aligned}
$$

The relations can be solved recursively where the quantities depend on the herd size $h$. Starting with an empty barn $(h=0)$ for which $L_{i}(0)=\Lambda_{i}(0)=0$, we can subsequently compute the quantities $\mathrm{W}_{i}(h), S_{i}(h), \Lambda_{i}(h), Q_{i}(h)$ and $L_{i}(h)$ for $h=1, \ldots, H$ by means of the relations formulated earlier.

Based on $Q_{i}(H)$ and $L_{i}(H)$ we can compute an approximation for the queue length probabilities. Let $p_{i}(k, H)$ denote the probability of $k$ cows (waiting or in service) in station $i$. For $k>c_{i}$ we set (as an approximation)

$$
p_{i}(k, H)=(H-k+1) \alpha p_{i}(k-1, H)=\ldots=\left(H-c_{i}\right)_{k} \alpha^{k-c_{i}} p_{i}\left(c_{i}, H\right),
$$

where $(n)_{k}=n(n-1) \ldots(n-k+1)$. The factor $H-k+1$ reflects the assumption that the arrival rate will be proportional to the number of cows that is not in station $i$. The two unknowns $\alpha$ and $p_{\mathrm{i}}\left(c_{\mathrm{i}}, H\right)$ are determined such that

$$
\sum_{k=c_{i}}^{H} p_{i}(k, H)=Q_{i}(H), \sum_{k=c_{i}}^{H}\left(k-c_{i}\right) p_{i}(k, H)=L_{i}(H) .
$$

The relative visit frequency to station $i$ is $v_{i}$ and the mean and standard deviations of the service time in station $i$ are denoted by $s_{i}$ and $\sigma_{i}$, respectively. The mean residual service time $R_{i}$ in station $i$ upon an arrival instant is approximated by Ross (1997): 


$$
R_{i}=\frac{s_{i}}{2}\left(1+\left(\frac{\sigma_{i}}{s_{i}}\right)^{2}\right) .
$$

The model was compared with real barn measurements: the arrival rates in the real farm were $4.56,6.84,4.98,7.43,3.97$ visits/h; to the concentrate self-feeder, forage lane, water troughs, cubicles, milking robot, respectively, and the corresponding AMVA results were $4.45,6.60,4.73,7.68,4.61$ visits/h, respectively. We determined the $95 \%$ confidence limits of $[-0.24,+0.31]$, and since this interval contains zero, there was no statistical evidence for rejecting the validity of our barn (at the $95 \%$ confidence level). The above queuing network model was proved statistically by Halachmi et al. (2000b). Specific literature references on validation as well as a case study of validation in the robotic milking barn can be found in Halachmi et al. (2001).

\subsection{Design criteria based on farmer's "aspiration level model"}

As the level of service increases (more places for feeding, drinking, milking, etc.), the cost of the barn increases, in contrast to the 'cost' of waiting cows, which decreases. The optimum service level occurs when the sum of the two costs is minimal. However, it is difficult to determine the 'cost' of cows' waiting time, therefore, we must seek other criteria for making design decisions. One possible design criterion could be to restricting the average waiting time at a given facility to 2 min per cow. This type of decision model is based on the use of an aspiration level that the service facility must satisfy. The farmer, designer or researcher can set the aspiration level according to specific farm conditions. An aspiration-level model recognizes the difficulty of estimating cost parameters and, therefore, provides a more straightforward analysis, that makes direct use of the operating characteristics of the barn. 'Optimal' is to be understood in the sense of satisfying certain aspiration levels set by the decision maker; these aspiration levels are taken to be the upper limiting values of the conflicting performance measures that the decision maker wishes to balance.

Let the design criteria be the aspiration levels for waiting time $\left(W_{\mathrm{i}}\right)$, queue length $\left(L_{\mathrm{i}}\right)$ and facility idle time $\left(1-\rho_{\mathrm{i}}\right)$. The optimum is the minimum number of servers, which satisfies the aspiration-level constraints $\left(\alpha_{i}, \beta_{i}\right.$ and $\left.\gamma_{i}\right)$. The solution can be determined for each facility, $i$ separately. $W_{i}$ and $L_{i}$ are monotonically decreasing functions and $\left(1-\rho_{i}\right)$ is a monotonically increasing function of $c_{i}$, and since only an integer solution has physical meaning, the optimum is determined visually by plotting $W, L$ and $(1-\rho)$ against $H$. By drawing $\alpha, \beta$ and $\gamma$ on the graph, the optimum integer $\left(c^{*}{ }_{i}\right)$ that satisfies all constraints (aspiration levels) can be determined. Naturally, if these conditions cannot be satisfied simultaneously, it is necessary to relax one or more restraints before a decision can be made.

\section{Results and applications}

The present study incorporates the mathematical algorithm into a practical design tool. By visual analysis of the barn performance, the designer can judge whether or 
not the layout fits the cows' needs for facility allocations. One of the practical problems related to this theory is that of a farmer wanting to determine the number of positions needed for their actual herd, and the distribution among the various facilities. Alternatively, the farmer might have a given total number of facilities installed in the barn and would like to determine the herd size for optimal utilization. Since the possibilities of interactive creative design are numerous, even for a single farm, only a few typical cases were chosen. The following tables and graphs are used to explain the algorithm and to demonstrate its scope in a given practical situation.

\subsection{Transitions of the cows among the barn facilities}

Table 1 presents transition probabilities of the cows between the barn facilities. It can be seen that cows' most popular movements appear to be between Forage lane and Cubicles and between Forage lane and Water troughs. If a 'forced routine' preventing these movements is applied, the cows will suffer a certain stress. It can be seen that in $90 \%$ of the cases, a CSF visit follows a robot visit. This suggests that the cow's main reason for going through the robot is the desire to get concentrates, and suggests that CSF, either in the milking stall or stand-alone, is an effective way to

Table 2

The design process; barn facility utilisation $(\rho)$, waiting time $(W)$ and queue length $(L)$ while varying number of cows $(H)$

\begin{tabular}{|c|c|c|c|c|c|c|c|c|c|c|c|c|}
\hline \multirow{2}{*}{$\begin{array}{l}H \\
\text { (cows) }\end{array}$} & \multicolumn{3}{|c|}{ CSF (1 feeding positions) } & \multicolumn{3}{|c|}{ Forage (12 positions) } & \multicolumn{3}{|c|}{ Cubicles (27 positions) } & \multicolumn{3}{|c|}{ Robot (2 stall) } \\
\hline & $\rho$ & $W(\min )$ & $L$ (cows) & $\rho$ & $W$ & $L$ & $\rho$ & $W$ & $L$ & $\rho$ & $W$ & $L$ \\
\hline 10 & 0.34 & 2.69 & 0.20 & 0.14 & 0.00 & 0.00 & 0.28 & 0.00 & 0.00 & 0.12 & 0.03 & 0.00 \\
\hline 15 & 0.50 & 5.19 & 0.57 & 0.20 & 0.00 & 0.00 & 0.41 & 0.00 & 0.00 & 0.18 & 0.08 & 0.01 \\
\hline 20 & 0.64 & 9.01 & 1.27 & 0.26 & 0.00 & 0.00 & 0.54 & 0.00 & 0.00 & 0.24 & 0.14 & 0.02 \\
\hline \multirow[t]{2}{*}{25} & 0.77 & 15.05 & 2.55 & 0.31 & 0.00 & 0.00 & 0.64 & 0.00 & 0.00 & 0.29 & 0.21 & 0.04 \\
\hline & \multicolumn{3}{|c|}{ CSF (2 feeding positions) } & \multicolumn{3}{|c|}{ Forage (12) } & \multicolumn{3}{|c|}{ Cubicles (27) } & \multicolumn{3}{|c|}{ Robot (2) } \\
\hline Cows & $\rho$ & $W$ & $L$ & $\rho$ & $W$ & $L$ & $\rho$ & $W$ & $L$ & $\rho$ & $W$ & $L$ \\
\hline 25 & 0.42 & 1.23 & 0.23 & 0.35 & 0.00 & 0.00 & 0.71 & 0.00 & 0.00 & 0.31 & 0.25 & 0.05 \\
\hline 30 & 0.50 & 1.90 & 0.42 & 0.41 & 0.01 & 0.00 & 0.84 & 1.00 & 0.38 & 0.37 & 0.38 & 0.09 \\
\hline 35 & 0.56 & 2.62 & 0.64 & 0.45 & 0.02 & 0.01 & 0.93 & 4.44 & 1.87 & 0.41 & 0.50 & 0.13 \\
\hline \multirow[t]{2}{*}{40} & 0.58 & 3.21 & 0.83 & 0.48 & 0.03 & 0.01 & 0.98 & 11.13 & 4.95 & 0.43 & 0.58 & 0.16 \\
\hline & \multicolumn{3}{|c|}{ CSF (3 feeding positions) } & \multicolumn{3}{|c|}{ Forage (12) } & \multicolumn{3}{|c|}{ Cubicles (50) } & \multicolumn{3}{|c|}{ Robot (2) } \\
\hline Cows & $\rho$ & $W$ & $L$ & $\rho$ & $W$ & $L$ & $\rho$ & $W$ & $L$ & $\rho$ & $W$ & $L$ \\
\hline 40 & 0.45 & 0.66 & 0.20 & 0.55 & 0.07 & 0.03 & 0.61 & 0.00 & 0.00 & 0.50 & 0.78 & 0.24 \\
\hline 50 & 0.56 & 1.31 & 0.48 & 0.68 & 0.36 & 0.20 & 0.76 & 0.00 & 0.00 & 0.62 & 1.42 & 0.54 \\
\hline 60 & 0.65 & 2.26 & 0.96 & 0.79 & 1.16 & 0.73 & 0.88 & 0.96 & 0.70 & 0.72 & 2.38 & 1.05 \\
\hline 65 & 0.68 & 2.80 & 1.25 & 0.83 & 1.82 & 1.21 & 0.92 & 2.28 & 1.77 & 0.75 & 2.96 & 1.38 \\
\hline
\end{tabular}

CSF, concentrate self-feeder; $H$, herd size, number of cows in the barn; $\rho$, utilization (or, $1-\rho$ is idle time) rate; $W$, waiting time in the queue for each individual cow, min.; $L$, queue length, cows. 
force a route. It can be seen that the frequency of transition of a state to itself is not zero, since a state can be succeeded by itself. For example, a cow can leave a water trough and move to another one, or can even return to the original trough after a few minutes without visiting any other facility. Adding the (artificial) 'walking' facility ensures that the frequency of the transition of a state to itself is zero; in fact, all transitions are to or from the 'walking facility' (Fig. 2 includes 'walking').

The stable probability distribution $\left(q_{i}\right.$, Fig. 1) can be interpreted as follows: if the barn is observed after a sufficiently long time (after the influence of the initial state of the system has diminished), the probability of finding a randomly selected cow in facility $i$ is given by $q_{i}$. And $q_{i}$ represents the mutual interactions among the facilities, imposed by using a milking robot. Therefore, $q_{i}$ appears to be the fractions of the facility usage that should ideally be allocated to satisfy the cow's behaviour pattern and animal welfare needs.

\subsection{Determining the design starting point}

The target was a 60-cow herd. The initial point was the barn configuration described by Halachmi et al. (2000a). Table 2 predicts what will happen if the number of cows is increased and it shows how we can tune the system by adding servers as needed. It can be seen that the starting configuration (one CSF, 12 forage lane positions, three water troughs, 27 cubicles, and two milking-robot stalls) may accommodate up to 25 cows. Above that number, the utilization of the CSF is rather intensive (77\%), which results in a long queue (2.5 cows) and waiting time (15 min). Adding one CSF enables the system to accommodate up to 40 cows, in which case the bottleneck appears to be the number of cubicles and the CSF. Adding 23 cubicles (to make it 50) and a further CSF (for a total of three) gives optimum balanced performance of all the facilities, satisfies the aspiration levels (short queue: less than two cows are waiting, less than 3 min waiting time), and minimizes costs (facility utilization is intensive: $68,83,92$, and $75 \%$ ).

\subsection{The design process}

The next step in the design process is to use the GUI to fine-tune the optimal number of servers for each facility separately. Consider the forage lane. First, the farmer has to specify his aspiration levels for queue length, waiting time, and utilization for each individual facility. For example, queue length: 'up to one cow is waiting' $\left(\beta=1_{\text {cows }}\right)$, waiting time: 'less than 1.5 minutes' $(\alpha=1.5 \mathrm{~min})$, and utilization level: above $70 \%$ (i.e. idle-time less than $30 \%, \gamma=0.3$ ). In Fig. 3, forage-lane performance is shown as a function of herd size for a fixed number of forage lane positions (12), and aspiration-levels are shown. On the one hand, if the herd contains more than 50 cows, the utilization $\geqslant 70 \%$ (or idle-time $\leqslant 30 \%$ ). On the other hand, to meet animal-welfare aspiration levels $(\alpha$ and $\beta)$, the herd size should not exceed 60 cows. In order to meet all aspiration levels, the herd should comprise 50-60 cows. Therefore, if the cowshed is built on a 1:5 ratio, i.e. 12 forage yoke gates for 60 cows, the average queue length is expected to be one cow and the expected waiting 

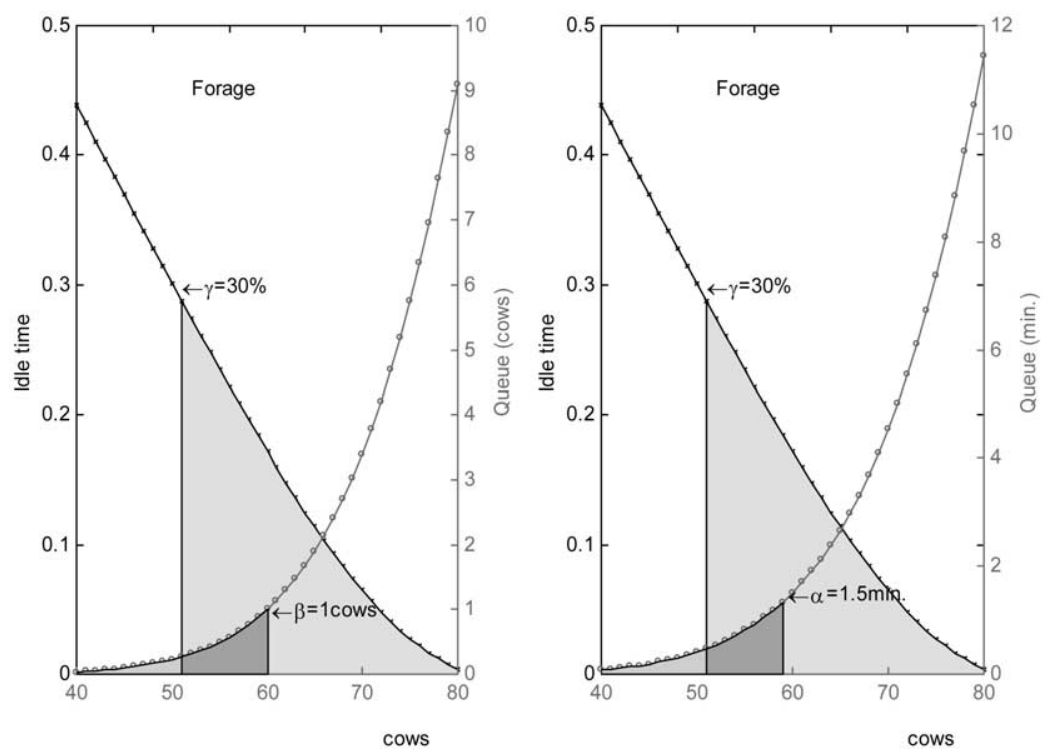

Fig. 3. Forage lane performance and aspiration levels as a function of the number of cows (40-80), using a fixed number of forage lane positions (12). The system performance measures are waiting time, queue length and idle time. The aspiration levels are $\alpha=1.5 \mathrm{~min}, \beta=1$ cows and $\gamma=30 \%$.

time is $1.5 \mathrm{~min}$. To address with animal welfare concerns, it is recommended to build on a 0.25 ratio ( 48 cows), which gives a rather short queue (theoretically, 0.25 cow waiting $\downarrow$ min). Either case would be more economical than the existing situation, a 1:1 ratio in a traditional farm with a milking parlour. It can be seen (Fig. 4) that 52 cubicles are needed in order to meet the same aspiration levels for 60 cows. The iterative design and analysis described earlier can be repeated for all the facilities in the barn, until an 'optimal design' has been achieved.

The combination of all the facilities in the barn into one network model prevents a 'bottleneck': the designer should compare the working loads (utilization and queue) between facilities. Fig. 5 shows the overall performances of a barn; in this second example, we assume that a designer has a herd size, $H$ of 140 cows and wants to vary the number of servers. It can be seen that, if the configuration is six CSFs, 27 forage lane positions, 115 cubicles, and four milking robot stalls, then with up to 130 cows the queue length is moderate, but once herd the size exceeds 140 cows the queue for the cubicles grows sharply. Since the costs of the robot are relatively high, its aspiration-levels have been slightly adjusted: idle time $=25 \%$, and a queue of three cows waits for $3 \mathrm{~min}$ (instead of $30 \%, 1 \mathrm{cow}, 1.5 \mathrm{~min}$ ). It can be seen that given these aspiration levels, the barn configuration accommodates up to 140 cows, whereas a herd of less than 120 cows results in inefficient use of the facilities (long idle time).

Water troughs (nine units) were taken into account. But since they have no influence on the queue (low utilization, $\rho=0.38$ for 140 cows, and $W=L \approx 0$ ) and relatively low installation and operation costs, they were suppressed from this computer screen in order to keep it simple, and to allow more interesting facilities to be presented. 

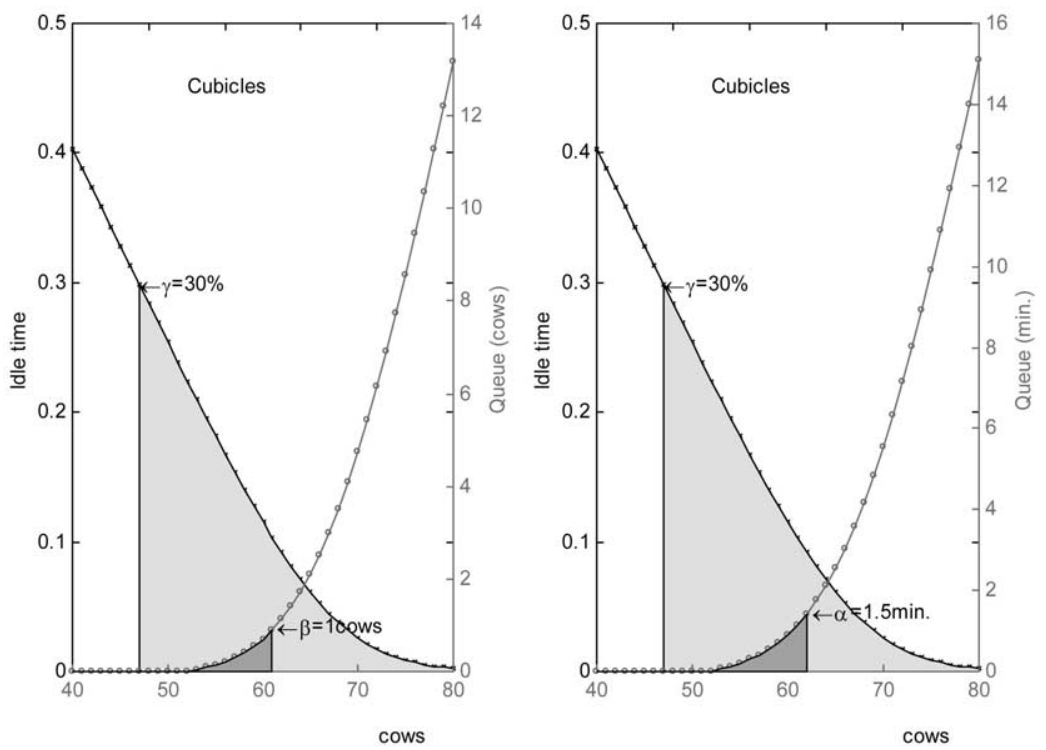

Fig. 4. Cubicle performance and aspiration levels as a function of the number of cows (40-80) using a fixed number of cubicles (52). The system performance measures are waiting time, queue length and idle time. The aspiration levels are $\alpha=1.5 \mathrm{~min}, \beta=1$ cows and $\gamma=30 \%$.
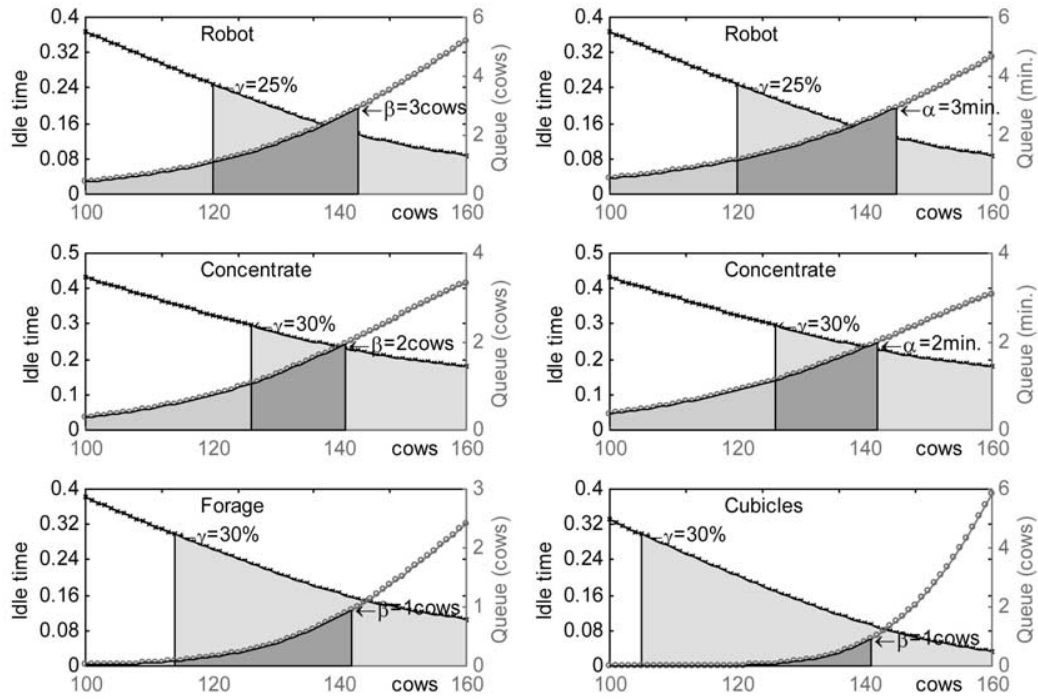

Fig. 5. Performance of the entire barn: six concentrate feeders, 27 forage lane positions, 115 cubicles, and four milking robot stalls as function of number of cows (100-160). The system performance measures are waiting time, queue length and idle time. The robot' aspiration-levels are $\alpha=3 \mathrm{~min}, \beta=3$ cows, $\gamma=25 \%$, elsewhere, $\alpha=1.5 \mathrm{~min}, \beta=1 \mathrm{cow}$ and $\gamma=30 \%$. 
The following utilisation $(\rho)$ ratings summarise the 'balanced design' that has been achieved, (herd size is 140 cows): $\rho_{\text {Conc }}=0.77 ; \rho_{\text {Forage }}=0.84 ; \quad \rho_{\text {Water }}=0.38$; $\rho_{\text {Cubicles }}=0.90 ; \rho_{\text {Robot }}=0.85$. The average queue lengths are, $L_{\text {Conc }}=1.88 ; L_{\mathrm{Fo}}$ rage $=0.83 ; L$ Water $=0.00 ; L_{\text {Cubicles }}=0.80 ; L_{\text {Robot }}=2.59$ cows. The design process has been completed.

\section{Discussion}

It is a common knowledge that a cow spends most of her time in the cubicle area, less time in the forage lane, etc. but $q$ expresses the exact ratio between the facilities, an important piece of information in itself, which is also in agreement with the observation by Uetake et al. (1997).

In the present version of the model, all cows are treated the same. This means that the waiting times for dominant and low-ranking cows are equal, which is obviously a simplification. Cows' actual behaviour shows the effects of social rank; for example, lower-ranking cows spend longer in the waiting area, in front of the robot (Ketelaar-de Lauwere et al., 1996). Queuing theory provides an additional feature: the 'priority queue', which will make it possible, in the future, to incorporate the impact of social rank into the model. Seasonal effects on cow behaviour, such as winter calving, and slower activity patterns during hot summer days coupled with enhanced activity at night (Halachmi et al., 2002) could be quantified into the transition matrix in future research.

The conclusions from the present queuing model are valid only if the steady-state condition is properly maintained. For example, if forage is offered once or twice a day instead of continuously, this stochastic steady-state model would no longer hold. A field experiment has shown that a steady state can be achieved in the barn (Halachmi, 1999). Increasing the herd size may increase the time necessary to reach social stability (Kondo and Hurnik, 1990), and competition for resources such as water, feed or resting space also has a pronounced effect on this time, as do the group composition, age, and social experience of the animals. But we assume that a sufficiently long time had elapsed from the moment of assembling the cows into a herd, so that a given group could be considered to be socially stabilized.

Further research could take the forms of simulations and economic optimization. Sometimes simulation models require fewer simplifying assumptions than the network model does (Halachmi, 2000; Halachmi et al., in press), and economic analysis would be possible if the queue cost of the cows could be quantified in terms of performance, and by attaching cost values to the aspiration-level model.

\section{Conclusion}

This study has contributed towards the development of a farm-designing tool based on cow behaviour, cow welfare needs, queuing theory, Markov process and heuristic optimization. The tool enables an RMB designer to optimise the allocation 
of facilities in the barn by specifying 'aspiration levels' (queue length, waiting time, and facility utilisation), and it appears to be a practical tool for evaluating the performance of configurations of facilities, of the entire network, or of each facility separately. Visual analysis of the barn performance enables the designer to judge whether the layout meets the cows' needs for facilities. Special care has been taken to produce a user-friendly interface.

The transition probability matrix shows that in $90 \%$ of the cases, a CSF visit follows a robot visit. This suggests that the main reason for going through the robot is to obtain concentrates. Therefore, the CSF (either stand-alone or in the milking stall) forms an effective means to force a 'traffic routine'. The most popular movements appear to be between forage-lane and cubicles and between forage-lane and water troughs. If a forced routine prevents these movements, the cows may suffer some stress.

The possibilities of interactive creative design are numerous, even for a single farm; therefore only two simple cases were selected:

1. On the particular farm, presented above $(\beta=1$ cow, $\alpha=15$ min, utilization over $70 \%$, one CSF, 12 forage positions,..., etc.), the following conclusions were reached: if the herd is larger than 50 cows, the forage lane utilization $\geqslant 70 \%$ (or idle-time $\leqslant 30 \%$ ). Also, to meet animal welfare aspiration levels $(\alpha$ and $\beta$ ), the herd size should not exceed 60 cows. Therefore, the herd should comprise 50-60 cows.

2. On the second farm, presented earlier, the following conclusions were reached. A barn configuration of six CSFs, 27 forage lane positions, 115 cubicles, and four milking robot stalls, is enough for up to 140 cows, and fewer than 120 cows results in inefficient usage of the facilities (long idle time). The average robot idle time $=25 \%$; queue length $=3$ waiting cows; each cows waits about $3 \mathrm{~min}$.

Network techniques for the analysis and design of livestock housing are still uncommon. This study demonstrates, however, that such techniques can be useful for designing to meet both economic and animal welfare needs.

\section{References}

Acillona, J., Perez, C., 1996a. The free stall housing design. dimensional analysis. In: Proceedings of International Agricultural Engineering Conference, Madrid, Spain (paper 96B-084).

Acillona, J., Perez, C., 1996B. Dimensional parameters at the free stall housing design. number of cubicles. In: Proceedings of International Agricultural Engineering Conference, Madrid, Spain (paper 96B-085).

Armstrong, D.V., Daugherty, L.S., Galton, D.M., Knoblauch, W.A., 1992. Analysis of capital investment in robotic milking systems for U.S. dairy farms. In: Ipema, A.H., Lippus, A.C., Metz, J.H.M., Rossing, W. (Eds.), International Symposium on Prospects for Automatic Milking. Pudoc Scientific Publishers, Wageningen (Netherlands), pp. 432-439.

Baskett, F., Chandy, K.M., Muntz, R.R., Palacios, F.G., 1975. Open, closed and mixed networks of 
queues with different classes of customers. Journal of the Association of Computing Machinery 22 (2), 248-260.

Devir, S., 1995. The Dairy Control and Management System in the Robotic Milking Farm. PhD Thesis, Wageningen Agricultural University, Wageningen, The Netherlands.

Grimmett, G.R., Stirzaker, D.R., 1992. Probability and Random Processes. Oxford University Press, UK.

Gross, D., Harris, C.M., 1998. Fundamentals of queuing theory, third ed. Wiley \& Sons, New York.

Halachmi, I., 1999. Designing Methodology for the Robotic Milking Barn; Modelling, Simulation, Validation and Optimisation. PhD Thesis, Wageningen University, The Netherlands.

Halachmi, I., 2000. Designing the optimal robotic barn, Part 2: Behavioural-based simulation. Journal of Agricultural Engineering Research 77 (1), 67-79.

Halachmi, I., Metz, J.H.M., Maltz, E., Dijkhuizend, A.A., Speelman, L., 2000. Designing the optimal robotic barn, part 1: quantifying facility usage. Journal of Agricultural Engineering Research 76, 37-49.

Halachmi, I., Adan, I.J.B.F., van der Wal, J., Heesterbeek, J.A.P., van Beek, P., 2000. The design of robotic dairy barns and using closed queuing networks. European Journal of Operation Research 124 (3), 437-446.

Halachmi, I., Dzidic, A., Metz, J.H.M., Speelman, L., Dijkhuizen, A.A., Kleijnen, J.P.C., 2001. Validation of a simulation model for robotic milking barn design. European Journal of Operation Research 134 (3), 165-176.

Halachmi, I., Metz, J.H.M., van't Land, A., Halachmi, S., Kleijnen, J.P.C. Optimal Facility Allocation in a Robotic Milking Barn (in press).

Halachmi, I., Maltz, E., Livshin, N., Antler, A., Ben-Ghedalia, D., Miron, J., 2002. Feeding behavior of dairy cows in hot climate. joint meeting: American Dairy Science Association, American Society of Animal Science, Canadian Society of Animal Science (ADSA/ASAS/CSAS), 21-25 July, Quebec, Canada.

Hillier, F.S., Lieberman, G.J., 1986. Introduction to operations research, fourth ed. Holden-Day, Oakland, CA.

Hogeveen, H., van Lent, A.J.H., Jagtenberg, C.J., 1998. Free and one-way cow traffic in combination with automatic milking. In: Chastain, J.P. (Ed.), Fourth International Dairy Housing Conference. Published by ASAE, St. Louis, Missouri, pp. 80-87.

Hillerton, J.E., Winter, A., 1992. The effect of frequent milking on udder physiology and health. In: Ipema, A.H., Lippus, A.C., Metz, J.H.M. (Eds.), International Symposium on Prospects for Automatic Milking. Rossing, W., Pudoc Scientific Publishers, Wageningen (Netherlands), pp. 201-212.

Ipema, A.H., 1997. Integration of robotic milking in dairy housing systems Review of cow traffic and milking capacity aspects. Computers and Electronics in Agriculture 17 (1), 79-94.

Ketelaar-de-Lauwere, C.C., Devir, S., Metz, J.H.M., 1996. The influence of social hierarchy on the time budget of cows and their visits to an automatic milking system. Applied Animal Behaviour Science 49 (2), 199-211.

Ketelaar-de-Lauwere, C.C., Hendriks, M.M.W.B., Metz, J.H.M., Schouten, W.G.P., 1998. Behaviour of dairy cows under free or forced cow traffic in a simulated automatic milking system environment. Applied Animal Behaviour Science 56 (1), 13-28.

Kleinrock, L., 1975. Queueing Systems, Vol. 1: Theory, Vol. 2: Computer Applications. Wiley Press, New York.

Kondo, S., Hurnik, J.F., 1990. Stabilization of social hierarchy in dairy cows. Applied Animal Behaviour Science 27, 287-297.

Lemoine Austin, J., 1977. Networks of queues- A survey of equilibrium analysis. Management Science 24 (4), 464-481.

Lind, O., Ipema, A.H., de Koning, C., Mottram, T.T., Hermann, H.J., 2000. Automatic milking: reality, challenges and opportunities. In: Hogeveen, H., Meijering (Eds.) Proceedings of 'robotic Milking International Symposium'. 17-19 August, Wageningen Pers Lelystad, Netherlands.

Lindley, J.A., Whitaker, J.H., 1996. Agricultural Buildings and Structures, revised ed. Publisher: St. Joseph, ASAE, USA.

Livshin, N., Maltz, E., Edan, Y., 1995. Regularity of dairy cow feeding behaviour with computer-controlled feeders. Journal of Dairy Science 78 (2), 296-304. 
Menzi, W., Chase, L. E., 1994. Feeding behaviour of cows housed in free stall barns. In: Proceedings of Third International Dairy Housing Conference. 'Dairy Systems for The 21 st Century', Orlando, Florida, pp. 829-833.

Murphy, M.R., 1992. Water metabolism of dairy cattle. Journal of Dairy Science 75 (1), 326-333.

Prescott, N.B., Mottram, T.T., Webster, A.J.F., 1998. Relative motivations of dairy cows to be milked or fed in Y-maze and an automatic milking system. Applied Animal Behaviour Science 57, 23-33.

Ross, S.M., 1997. Introduction to Probability Models. Academic Press, MA, USA.

Rossing, W., Aurik, E., Smit, W., 1998. Robot milking systems and the integration in the dairy farm. In: Chastain, J.P. (Ed.), Fourth International Dairy Housing Conference, 28-30 January. Published by ASAE, St. Louis, Missouri, pp. 61-70.

Rossing, W., Hogewerf, P.H., 1997. State of the art of automatic milking systems. Computers and Electronics in Agriculture 17 (1), 1-17.

Shalit, U., Maltz, E., Silanikove, N., Berman, A., 1991. Water, sodium, potassium, and chlorine metabolism of dairy cows at the onset of lactation in hot weather. Journal of Dairy Science 74 (6), 1874 1883.

Silanikove, N., Maltz, E., Halevi, A., Shinder, D., 1997. Metabolism of water, sodium, potassium, and chlorine by high yielding dairy cows at the onset of lactation. Journal of Dairy Science 80 (5), 949-956.

Stefanowska, J., Devir, S., Hogeveen, H., 1997. Time study on dairy cows in an automatic milking system with a selection unit one-way cow traffic. Canadian Agricultural Engineering 39, 221-229.

Sonck, B.R., 1996. Labour Organisation on Robotic Milking Dairy Farms. PhD Thesis, Wageningen Agricultural University, Wageningen, The Netherlands.

Uetake, K., Hurnik, J.F., Johnson, L., 1997. Effect of music on voluntary approach of dairy cows to an automatic milking system. Applied Animal Behaviour Science 53 (3), 175-182.

Van Beek, P., 1975. An application of the Diffusion Approximation Technique to Store-and-forward Computer Network Models (Technical Report IDR-R-vbk/7508/3005). Eindhoven, The Netherlands.

van der Linde, R., Lubberink, J., 1992. Robotic milking system (RMS): design and performance. In: Ipema, A.H., Lippus, A.C., Metz, J.H.M., Rossing, W. (Eds.), International Symposium on Prospects for Automatic Milking. Pudoc Scientific Publishers, Wageningen (Netherlands), pp. 55-62.

Van, Vliet M., 1991. Optimization of Manufacturing System Design. PhD Thesis, Erasmus University, Rotterdam, The Netherlands.

Wierenga, H.K., Hopster, H., 1990. The significance of cubicles for the behaviour of dairy cows. Applied Animal Behaviour Science 26, 309-337.

Wierenga, H.K., Hopster, H., 1991. Timing of visits to the concentrates feeding station by dairy cows. Applied animal behaviour science 30, 247-271.

Wierenga, H.K., Metz, J.H.M., 1986. Lying behaviour of dairy cows influenced by crowding. In: Nichelmann, M. (Ed.), Ethnology of Domestic Animals. Privat, I.E.C, Toulouse, pp. 61-66.

Wilde, C.J., Peaker, M., 1990. Autocrine control of milk production. Journal of Agricultural Science 114, $235-238$. 